

\title{
CONFINEMENT OF FUSION REACTION PRODUCTS DURING THE FISHBONE INSTABILITY
}

\author{
W.W. HEIDBRINK, RALPH HAY, and J.D. STRACHAN \\ Plasma Physics Laboratory, \\ Princeton University \\ Princeton, New Jersey, \\ United States of America
}

\begin{abstract}
The presence of fishbone events in the PDX tokamak is currelated with a reduction in the burnup of $0.8 \mathrm{MeV}{ }^{3} \mathrm{He}$ ions. This reduction is probably caused by distortion of the ${ }^{3} \mathrm{He}$ drift orbits in the helical magnetic fields associated with the instability, resulting in the loss of about $70 \%$ of the confined ${ }^{3} \mathrm{He}$ ions in a moderately strong fishbone. Such a nonresonant loss of particles with large orbits indicates that fishbone events may influence $3.5 \mathrm{MeV}$ alphas in ignition experiments.
\end{abstract}

\section{DISCLAIMER}

account of wark sponsared by an agency of the United States This report was prepared as an account of work sponsere jny agency thercof, nor any of their Government. Neither the United Stales Governes or assumes any legal liability or responsiemployees, makes an: warranty, express or implied. or assumes any loga lability or icspoct, or bility ior the accuracy, completeness, or usefulness of any information, anparatyed rights. Referbility ior the accuracy, complectess, or use would not inlringe privalely owned rights. Referprocess disclosed, or reperein to any specific commercial producl, process, or service by trade name, traderente manufacturer, or otherwise does not necessarily constitute or imply its cndorseinent, recome mendation, or faroring by the United Stales Government of any agency thereor. The we the and opinions of authos. expressed hercin do not

Unitod Steles Government or any agency thercol. 
In PDX neu1 ral beam heated discharges a new instability called thr. "fishbone" instability was observed. ${ }^{1.2}$ The instability was associated with a siguificant loss of injected beas ions, resulting in the loss of as much as $20-40)^{\mathrm{b}}$ of the total beam heating power. ${ }^{2}$ The fishbone was identified as a large $n=1, m=1$ incenal kink node that also excites $n=1, m=2,3,4$ MHD modes. ${ }^{2,3}$ It was found theoretirally that largn losse's of injected beam ions are expee ted due to a resonance between the toroidal precession of the beam ions and the rotation of the MHD modes. ${ }^{3}$ The theoretical predictions for mode-induced beam-ion loss are cons-stent with most features of the PDX measurements ${ }^{-6}$ of bean-ion loss during fishbones.

Fistibotion would be extremeiy important if $3.5 \mathrm{MeV}$ alphas were to induce a fishboneLis event or if they were to suffer losses when other entsgetis ions were excitith lishbones. In this paper, we present measurements of the $d\left({ }^{3} \mathrm{He}, \mathrm{p}\right) \alpha$ fusion reaction rate duriur $D^{0} \rightarrow$ $D^{+}$neutral beam injection that suggest that non-resonant $0.8 \mathrm{McV}{ }^{3} \mathrm{He}$ ions experjence severe losses during fishbone activity.

The $0.8 \mathrm{Me} \mathrm{V}^{3} \mathrm{He}$ ions are produced by the $d(d, n)^{3} \mathrm{He}$ fusion reaction and their production rate is determined by masuring the $2.5 \mathrm{MeV}$ neutron emission level. If a ${ }^{3} \mathrm{He}$ ion is conhued, then it slows down through the peak of the $d\left({ }^{3} \mathrm{He}, \mathrm{p}\right) \alpha$ cross section. The ${ }^{3} \mathrm{He}$ burnup the ratio of $15 \mathrm{MeV}$ protons produced in the $\mathrm{d}\left({ }^{3} \mathrm{He}, \mathrm{p}\right) \alpha$ fusion reartion to $0.8 \mathrm{MeV}{ }^{3} \mathrm{He}$ ions produced in the $\mathrm{d}(\mathrm{d}, \mathrm{n})^{3} \mathrm{He}$ fusion reaction) is a sensitive m(ysiure of the $0.8 \mathrm{MeV}{ }^{3} \mathrm{He}$ ion confinement. ${ }^{7}$ The absolute magnitude of the $15 \mathrm{MeV}$ proton emiasion was detected with $10 \mathrm{~ms}$ time response using a horizontally inserted surface barrier Jetector ${ }^{7,8}$ The absolute calibration was confirmed by puffing ${ }^{3} \mathrm{He}$ gas and taking the ${ }^{3}$ II density to be $\frac{1}{2}$ of the resulting rise in electron density. ${ }^{7}$ The absolute accuracy of the measurement of the emission is about a factor of two. The relative accuracy is determined prinarily by counting statistics.

Most fusion-produced ${ }^{3} \mathrm{He}$ ions are born near the hot center of the plasma. In PDX, about half of of the created $0.8 \mathrm{MeV}^{3} \mathrm{He}$ ions suffer classical orbit losses, with the majority of the losses occurring in the perpenaicular part of velocity space. ${ }^{7}$ Because the poloidal gyroradius depends inversely on poloidal field, the magnitưfe of theoe classical losses drops with increasing plasma current. Classically, confined $\mathrm{MeV}$ ions slow down predominately due to collisions with electrons, losing energy in a time approximately proportional to $T_{e}^{3 / 2} / n_{e}$. The probability of a $\mathrm{d}\left({ }^{3} \mathrm{He}, \mathrm{p}\right) \alpha$ reaction is proportional to the slowing-down tims and to the density of target deuterons $n_{d}$, su the classical burnup probability scales approximately as $n_{d} T_{e}^{3 / 2} / n_{c}$. Classically, the $\mathrm{d}\left({ }^{3} \mathrm{He}, \mathrm{p}\right) \alpha$ reaction rate is expected to depend on the sreation rate of ${ }^{3} \mathrm{He}$ ions (the $2.5 \mathrm{MeV}$ neutron emission), on the poloidal field 
distribution $\left(I_{p}\right)$, and on the electron temperature. ${ }^{7}$ Reductions in the $\mathrm{d}\left({ }^{3} \mathrm{He}, \mathrm{p}\right)$ a reaction rate below the classical level indicate that the ${ }^{3} \mathrm{He}$ ions are more poorly confined than classically predicted, that the spatial distribution of $\mathrm{d}(\mathrm{d}, \mathrm{n})^{3}$ He reactions is broader than predicted (resulting in increased classical losses), or that the ${ }^{3} \mathrm{He}$ ions lose cnergy more rapidly than classically predicted. ${ }^{7}$

The best $0.8 \mathrm{MeV}^{3} \mathrm{He}$ burnup data during fisbbones are from two PDX run sequences during divertor operation. On one discharge sequence (Fig. 1), the plasma current rose from $250 \mathrm{kA}$ to $340 \mathrm{kA}$; with a resulting $25 \%$ drop in the poloidal beta and a termination of fishbone activity (Fig. $1 \mathrm{a}, \mathrm{b}$ ) at about $450 \mathrm{~ms}$. The electron temperature ( $\simeq 13 \mathrm{keV}$ ) and beam power ( $4 \mathrm{MW}$ ) were approximately constant and the toroidal field was $14 \mathrm{kG}$. Within the experimental and theoretical uncertainties in measuring and predicting the ${ }^{3} \mathrm{He}$ burnup, ? the absolute magnitude of the $15 \mathrm{MeV}$ proton emission (Fig. 1c) is roughly comparable to the levels expected for classical ${ }^{3} \mathrm{He}$ burnup throughout the dischatge. Improved accuracy in the comparison of theory and experiment is obtained by normalizing the calculation and the experiment at $550 \mathrm{~ms}$ (i.e., saying the ${ }^{3} \mathrm{He}$ burnup is classical at $550 \mathrm{~ms}$ ) and examining the time evolution of the ${ }^{3} \mathrm{He}$ burnup. The magnitude of the ${ }^{3} \mathrm{He}$ burnup at $550 \mathrm{~ms}$ is close to the magnitude of the burnup measured previously in PDX discharges witb sawiooth MHD activity in which the ${ }^{3} \mathrm{He}$ burnup varied with plasma current and electron temperature approximately as expected, ${ }^{7}$ while the burnup earlier in the discharge falls below most of the previous observations. With this normalization, the measurements indicate that, in the presence of the fishbones, the ${ }^{3} \mathrm{He}$ burnup was about $\frac{1}{2}$ of the classical value. If we assume that a constant fraction of the beam ions was lost at each fishbone, then the $50 \mathrm{keV}$ deuterons (beam inns) had an average confinement time ${ }^{6}$ of $12 \rightarrow 17 \mathrm{~ms}$, while the instantaneous loss rate of the beam ious ${ }^{6}$ (as measured by the neutron decay rate during the fishbone) was about $1 \mathrm{~ms}$. The average ${ }^{3} \mathrm{He}$ confinement time ${ }^{7}$ was about $5 \mathrm{~ms}$, implying that $70 \pm 2 \sigma^{i} j$ of the $0.8 \mathrm{MeV}{ }^{3} \mathrm{He}$ ions were lost at each fishbone. Alternative interpretations for the reduction in ${ }^{3} \mathrm{He}$ burnup are that the $\mathrm{d}(\mathrm{d}, \mathrm{n})^{3} \mathrm{He}$ emission profile was a factor of 1.7 broader before $450 \mathrm{~ms}$ than arter $450 \mathrm{~ms}$ or that about $70 \%$ of the ions rapidly decelerated during each fishbone. Although the $\mathrm{d}(\mathrm{d}, \mathrm{n})^{3} \mathrm{He}$ enission profile may broaden instantaneously during a fishbone as beam-ions are expelled from the center of the plasma, for classical beam deposition, the average emission profile is not expected to be appreciably broader before $450 \mathrm{~ms}$ than after $450 \mathrm{~ms}$.

In a second run sequence with weaker fishbones (15\% drops in the neutron cmission). the ${ }^{3}$ He burnup was about $\frac{3}{4}$ of the expected classical value (Fig. 3.18 of Ref. 8 ).

The effect of fisbbones on the drift orbits of $0.8 \mathrm{MeV}{ }^{3} \mathrm{He}$ ions was studied numerically 
using a Monte Carlo code ${ }^{3}$ The fishbone magnetic field structure was modeled by helical $n=1, m=1,2,3$ modes rotating toroidally at $16 \mathrm{kHz}$. The radial distribution of $\mathbf{d}\left(d_{r} n\right)^{3} \mathrm{He}$ fusion reactions that produce the ${ }^{3} \mathrm{He}$ ions and the unperturbed field structure were chosen to approximate the experimental conditions of Fig. 1. The perturbed field structure was modeled as a square pulse of duration $500 \mu \mathrm{s}$ and the fraction of ${ }^{3} \mathrm{He}$ ions lost during the "fishbone" pulse was calculated as a function of mode amplitude (Fig. 2a). For a given mode amplitude. the predicted losses of $0.8 \mathrm{MeV}{ }^{2} \mathrm{He}$ ions excecd the losses predicted for $50 \mathrm{keV}$ beam ions by about a factor of two. This is in agreement with the experimenta! observations. Unlike the beam-ion losses, the computed ${ }^{3} \mathrm{He}$ losses are insensitive both to the duration of the fishbone and to the mode precession frequency in the range of $10-20 \mathrm{kHz}$ (Fig. 2b), indicating that the ${ }^{3} \mathrm{He}$ losses are not due to a resonance with the mode. Both co-going and counter-going ${ }^{3} \mathrm{He}$ ions are lost in roughly equal amounts. (Trapped ${ }^{3} \mathrm{He}$ ions are lost classically.) The radial distortion of the ${ }^{3} \mathrm{He}$ drift orbits is generally several times larger than the radial distortion of the flux surfaces alone. The numerical calculations suggest that the observed reduction in ${ }^{3} \mathrm{He}$ burnup is due primarily to additional orbit losses to the PDX vessel caused by distortion of ${ }^{3} \mathrm{He}$ drift orbits in the three-dimensional field created by the fishbone instability.

For field perturbations $\delta B_{\theta} / B_{\theta}$ of equal amplitude, the losses of fusion products on larger devices are expected to be less severe than on PDX since the ratio of poloidal gyroradius to plasma minor radius is smaller. In near-term ignition $(Q \simeq 1)$ experiments, however, the losses still are expected to be appreciable. For example, on TFTR $(a=80 \mathrm{~cm}$, $R=270 \mathrm{~cm})$ near $Q=1\left(B_{\mathrm{T}}=40 \mathrm{kG}, J_{p}=1.9 \mathrm{MA}\right)$ the presence of field perturbations as large as those ubserved in our PDX experiments $\left(\delta B_{\theta} / B_{T}=2 \times 10^{-3}\right)$ is predicted to increase the losses of $3.5 \mathrm{MeV}$ alphas from $8 \%$ in the absence of instabilities to $49 \%$ in the presence of fishbones.

In conclusion, the observed reduction in the $0.8 \mathrm{MeV}{ }^{3} \mathrm{He}$ burnup in the presence of PDX fishbones suggests that nos-resonant fusion pruducts can be lost in an MHD mode of sufficient amplitude. $3.5 \mathrm{MeV}$ alphas in an ignition experiment may experience losses even if the alpha population does not destabilize any modes.

We thank K. Bol and the PDX staff for their support, G. Estepp for technical assistance, and R. White for developing the Monte Carlo code. F. Tenney made the electron temperature measurements and K. McGuire supplied the Mirnov signal. The PLX project was supported by U.S. Department of Energy Contract No. DE-AC02-76-CHO-3073. 


\section{References}

1 D. Johnson et al., in Plasma Physics and Controlled Nuclear Fusion Resparch (IAEA, Baltimore, 1983) Vol. I, p. 9.

${ }^{2}$ K. McGuire et al., Phys. Rev. Lett. 50, 891 (1983).

3 R.B. White, R.J. Goldston, K. McGuire, A.H. Boozer, D.A. Monticello, and W. Park, Phys. Fluids 26, 2958 (1983).

4 P. Beiersdorfer, R. Kaita, and R.J. Goldston, Nucl. Fusion 24, 487 (1984).

5 D. Buchenauer, D.Q. Hwang, K. McGuire, and R.J. Goldston, "MHD Effects on Beam Ion Loss During Near Perpendicular Neutral Beam Injection", Proc. of Fourth Int. Symposium on Haatiug in Toroidal Plasmas, Rome (1984) to be published.

B J.D. Strachan, B. Grek, W. Heidbrink, D. Johnson, S. Kaye, H. Kugel, B. Leblanc, and K. McGuire, "Studies of Energetic Ion Confinement during Fishbone Events in PDX", to be published.

7 W.W Heidbrink, R.E. Chrien, and J.D. Strachan, Nucl. Fusion 23, 917 (1983).

8 W.W. Heidbrink, Tokamak Diagnostics using Fusion Products, Ph.D. Thesis, Princeton Univ., p. 66. (1984). 


\section{Figure Captions}

Fig. 1 Tine evolution of (a) the magnetic fuctuations from a Mirnov coil mounted near the outer wall. (b) the neutron cmission measured by an NE102A icintillator, and (c) the $15 \mathrm{MeV}$ proton emission from the $\mathrm{d}\left({ }^{3} \mathrm{He}, \mathrm{p}\right)$ o fusion reaction for a PDX plasma which evolved out of large fishbone activity at about $450 \mathrm{~ms}$. The shaded region in (c) is the calculated $15 \mathrm{MeV}$ proton emission based upon classical $0.8 \mathrm{MeV}^{3} \mathrm{He}$ ion produrtion, confinement, and slowing down using measurements of the time evolution of the plasma current and of the electron temperature (PHA). The calculation is normalized to experiment at about $550 \mathrm{~ms}$. The proton data are the average of four similar discbarges.

Fig. 2 (a) Fractional loss of $0.8 \mathrm{MeV}^{3} \mathrm{He}$ ions in a fishbone of $n=1, m=1$ mode amplitude $\delta B_{\theta} / B_{T}$. The open points are the results of Monte Carlo simulations with 3000 particles. The curve is a fit to the calculated points. The solid points are the ${ }^{3} \mathrm{He}$ lasses deduced assuming that the measured reduction in ${ }^{3} \mathrm{He}$ burnup is due to fisbbone losses of ${ }^{3} \mathrm{He}$ ions. The vertical error bars represent the uncertainty in relating the burnup reduction to the losses per fishbone. The mode ampiitude for the ${ }^{3} \mathrm{He}$ burnup data was determined by selecting the amplitude that correctly predicts the experimentally observed reduction in neutron emission; the horizontal error bars represent uncertainties in this amplitude due to uncertainties in the beam deposition and $q$ profiles. The amplitudes of the $m=1,2,3$ modes are assumed to be in the ratio $3.8: 2: 1$ and the mode rotates toroidally at $16 \mathrm{kHz}$. (b) Fractional loss of $0.8 \mathrm{MeV}^{3} \mathrm{He}$ ions as a function of mode precession frequency in a Esbbone with mode amplitude $\delta B_{\theta} / B_{T}$ of $2.2 \times 10^{-3}$. Compared to beam ions (Fig. 4 of Ref. 3), the ${ }^{3} \mathrm{He}$ ions are insensitive to changes in precession frequency, indicating that the ${ }^{3} \mathrm{He}$ losses are not due to mode-particle pumping. 

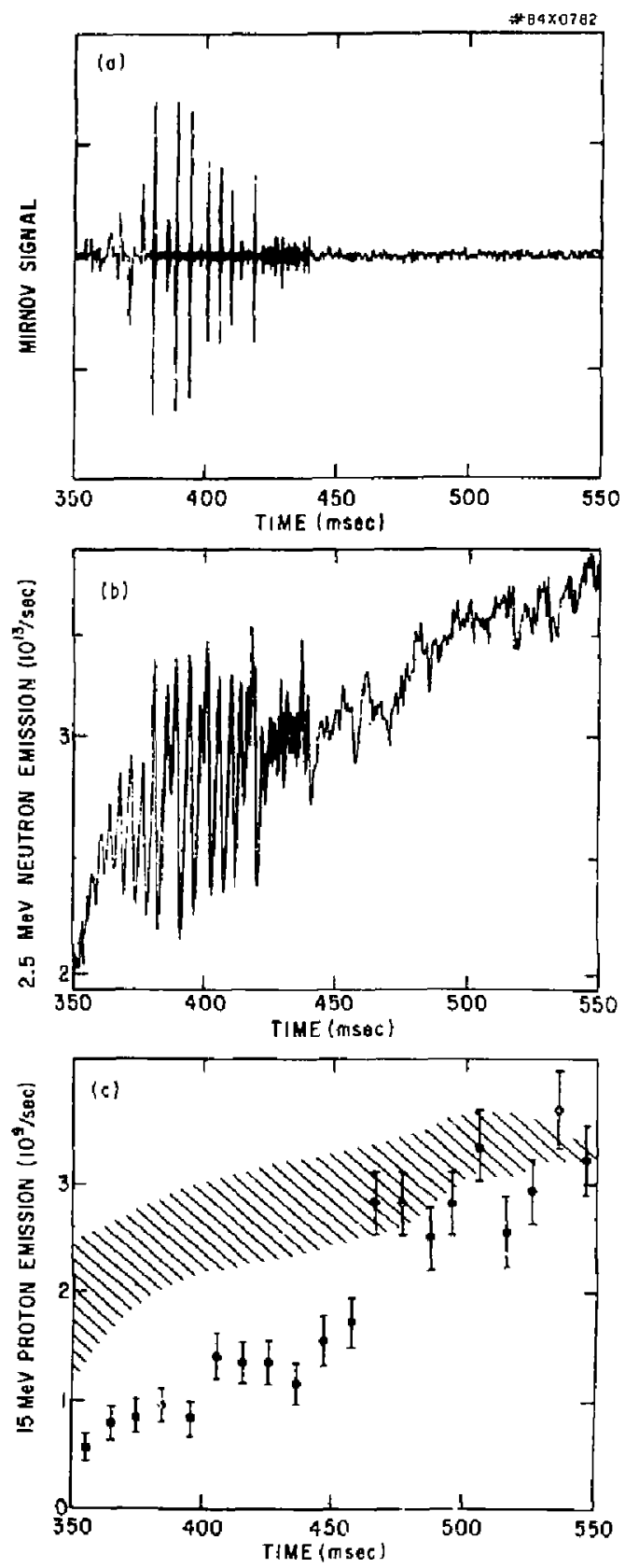

Fig. 1 

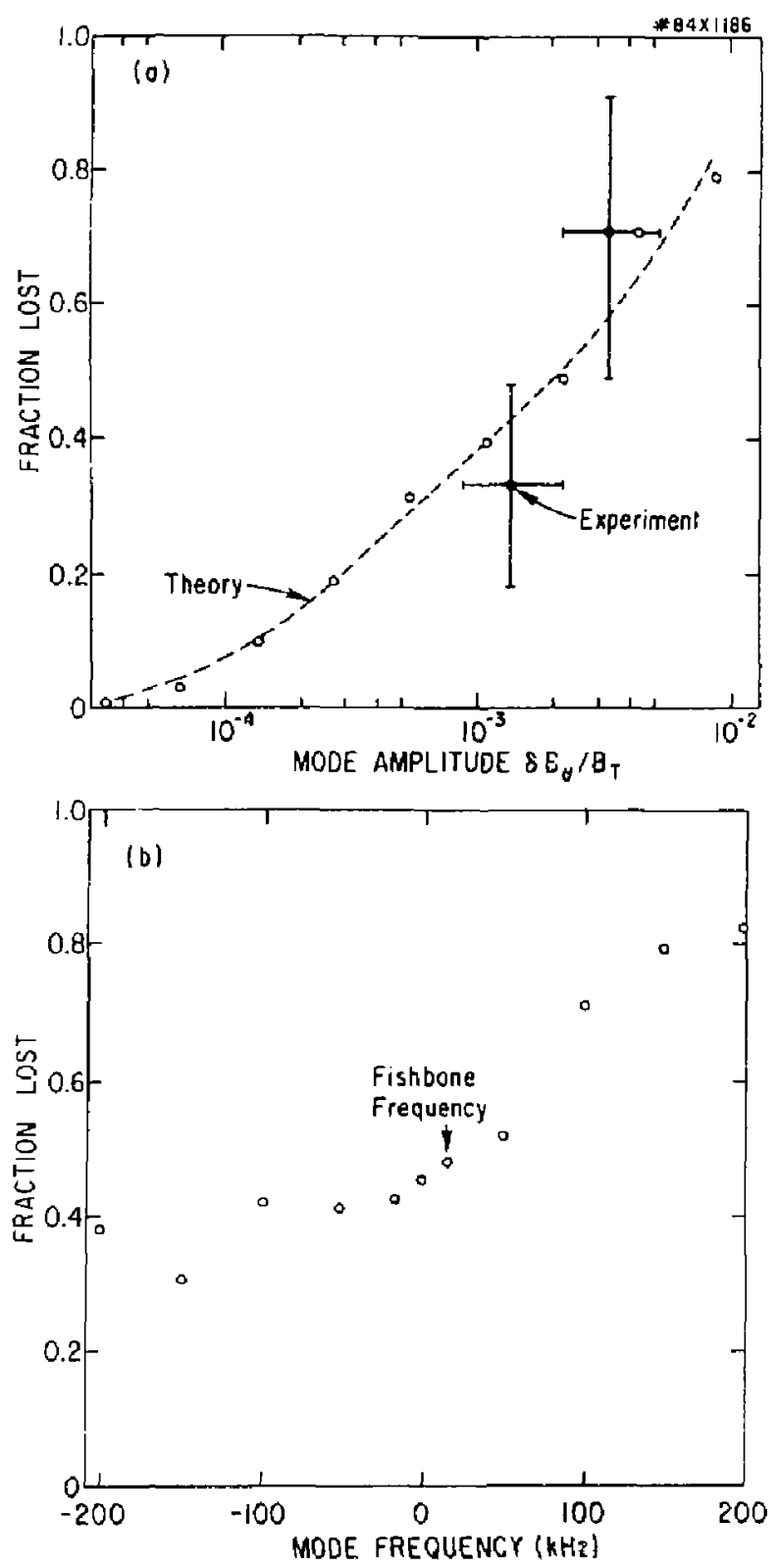

Fig. 2 


\section{EXTERNAL DISTRIBUTION IN ADOITION IO TIC UC-20}

Plasmo Res iob. Austro notil Univ, hustralia Dr. frenk d. Poclonl, Unkv of wollongong, aUSTRAL IA Prof. I.R. Jones, F।Inders "nlr.. AUSTRALIA Prof. M.th. Erennan, Und Syanor. AUSTRALIA Prod. F. Cef, Inst Theo Phrs, AuStR IA oed. Fronk verneest, Ins: theoretische, aElglum

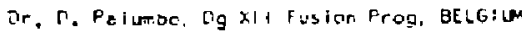

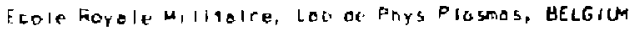

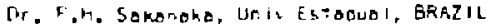

[?- C.F. Jemes, Univ al aI DeFete, CANADA

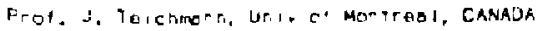
Dr, H.M. Shorsoaro, Unir $C^{\prime}$ Sosmetchemon. CANADA

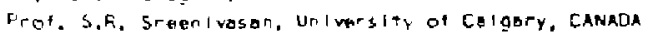

Frot. ilueor h. Jonnstori, INPSf neergle, CANADA

Ur. Honnas Gornor $C$, thin Er it.et Columbia, CANADA

ur. M.F. Eachuriskt, MPE Tecrnologies, Ine.. CANNOA

Ehonguc LI, SH ins. Physics, CHIHA

Libron, Tsire hus university. CHIMh

LIbrarlar, Insilitite of Physics, ChINA

inst Plesme Fhys, Acederile Sinlco, CHina

Dr. Setor Lukac, Momenskahe Univ, CZEChoslovakia

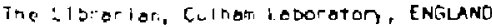

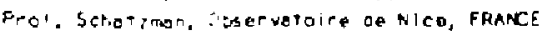

J, Rocet, Centrob, franze

GM Dures Lit:o $\checkmark$. AM Dupes a iberer, FaAnce

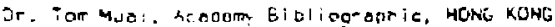

Frearin: - leror, Cert kes Inst Dhrs, Humgafy

in. S.r. Trehen, Fanjet Unluarslty, idola

Dr. Indra, Morior Lel Das, Bonaros Hindu Unly, INDiA

Dr. L, R. Chovas, South Guiarat Unlv, IND|A

r. R.k. Chnoledi, var Rueri Marg, INDIA

F. Kam, Physichl hesearch bou, InDIA

[ar. Phillip hosenal. Igrael inst Tech, igrael

Fro.. S. Cupermon, izl Avi. UnI uars Ity, ISTREL

Fro. C. Rostogni, UAiv di Podove, ITALT

Llorarion, In:'l LT inoo Phys. I The

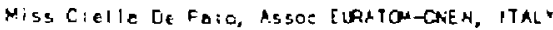

Eldiliotoco, de: CNF EURATLN, ITAi

Dr. 1-. Tame-c, Tosnide kes \& Der, JAPAM

Fre., M. Yoshikaro, JAERI, Toko, Fes Es?, JAPAN

Frot. i. Licnioe. Untverstty of Tokyc. JaPhh

Fesecret. Into Conter, Nogate unlversity. JaPan

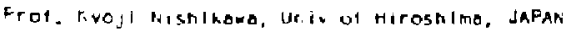

Erel. Sigern hori, Jhekl, Janah

L Ibrary, Kyotio Jriverslity, JAPak

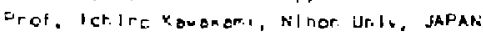

Frs'. Setost, tor, "Yushu Unlversigy, Japar

Tech Inte Eiviston, Koras atomic Enargr, KOREA

Ur, K. Englanc, Cluaec Universitarla, MExico

Etollotheok, Fon-Inst Visor FIasme, NETHERLANDS

Prot. E.5. Lilev, Universliy of WOIkOTO. NEW ZEALANO

Jr. Suresh C. Srerma, Univ of Calabar, NIGERIA
Prof. J.A.C. Cabrol, Inst Super lor Toeh, PORTUGAL Or. Oetovlon Patrus, AL I CLRA Unlmarsity. ROMAnia Prot. M.A. Meliberg. Universlty of Notol, SC MFRICA Dr. Jabon de villiars, Atomic Enargr Ba, SE AFRICA Fuslar Dly. Librery. JEN, SPAll,

Prof. Mans Wlinolmson, Cholmers Uhly Toch, SWEDEN Or. Lannert Stantio, Unlvarsity of UMEA, SWEOEN Library, Royel inst tecn, 5mEDEA

Dr. Erik T. Marison, UDpsals Unlvarsilat, SWEDEN Contre de focharchosen, Ecole 10 irtock Fad, SwITZELAND Dr. W.L. Weiso. Not'l Eur stano, USA

Dr. M. Stacey, Georg Inst Tech, USA Or. S.T. WU, UnI Aloodra, USA

Prol. Norman L. Oloson, UnIv $\leq$ Flo-ldo, Us, Dr. Benjomin Ma, lowa State Unlv, USA Prot. Magne Kristlansen. Texas Tacr unir, isA Dr. Roymand Askem, Audurn Un 1., USk Dr. V.T. Tolok, Mharkov Phys Toch Ins, LES Dr. D.O. Riyutay, SIterion Acoo SCl, USSh Or. G.A. Elisene, Kurchetov Instlitute, LSSE Or. Y.A, Glukhikh, Inst Eloctromhysleal, USSh Institure Gon. Pnysles, US\$ुF

Prot. T.d. Boro, Univ Colloge N Woles, MALES

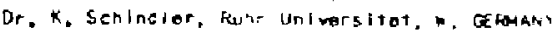
Huc loar Res Estat, Jullat l.Ta, M. Gepamawr

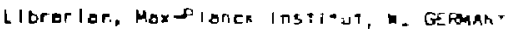

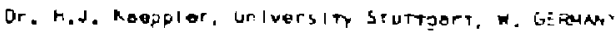
Blbllothok. Insi Flasmeforsenung. H. Getoman. 